\title{
Microstructure prediction during incremental processes for hot forming of 718 alloy
}

\author{
DUMONT Christian ${ }^{1, a}$, GEORGES Eric ${ }^{1, b}$ \\ ${ }^{1}$ Aubert \& Duval, Site des Ancizes, BP1, 63770 Les Ancizes Cedex, FRANCE \\ ${ }^{2}$ Aubert \& Duval, Site de Pamiers, BP173, 09102 Pamiers Cedex, FRANCE \\ achristian.dumont@eramet-aubertduval.com, ${ }^{\mathrm{b}}$ eric.georges@eramet-aubertduval.com
}

Key words : 718 alloy, microstructure, recrystallization, modelling, thermomechanical processing, bar rolling

\begin{abstract}
Main works on microstructure prediction on superalloys during hot forming processes deal with close die forging of 718 alloy. In this paper, we focused our interest towards incremental hot forming process. In that case, matters become more complex, due to the partially recrystallized microstructure we have to take into account at the beginning of each pass. An original method is presented in this paper, still using a phenomenological approach, according to Avrami formulation, with two main additional assumptions, in order to carry out computation on microstructure evolution during the process. Examples with comparisons between real and computed microstructure (recristallyzed fraction, different populations of grain size) enable us to valid our model for bar forging.
\end{abstract}

\section{Introduction: state of art in microstructure prediction}

718 alloy is still widely used for disks in aircraft engines (like low pressure turbine, high pressure compressor, etc ...). Improvement of existing forging route or development of new ones is now systematically achieved by mean of modelling, including models for prediction of microstructures. It is possible to find in literature many papers with different approaches:

- Purely phenomenological model built on Johnson-Mehl-Avrami formulations

- Physical models taking into account all the events involved in recrystallization (generation and annihilation of dislocations, sub-grains rotations, etc...)

- More specific models with varied numerical techniques (cellular automaton, neuronal networks, etc...)

Calculations in these models are essentially devoted to close die forging and Aubert \& Duval has developed its own model, based on Avrami formulation described in other publications [1]. This process can involve more than one forging pass. However, when the parts are systematically reheated in furnaces between each stroke, a new homogeneous microstructure can be considered as a new deformation sequence starts, owing to the almost full completion of recrystallization mechanism between two passes. Such assumption becomes invalid for incremental processes such as bar rolling or ingot conversion: time between two passes is short enough so that strain hardening effect can remain in grains. Many works in literature deal with this matter, but essentially for steels and rather few papers concern superalloys. C.A. DANDRE and col. [2] or B. ANTOLOVICH and M. EVANS [3] have studied bar cogging on alloy 718, but phenomenon involved in multi-pass processes have not been studied in detail. Moreover, they still use Avrami formulation although this approach considers that the initial microstructure is fully recrystallized. 


\section{Strategies available for microstructure prediction in incremental processes}

In order to predict microstructure by Avrami formulation, in spite of partially recrystallized microstructure, three kinds of strategies can be implemented:

1) Each family of grains, the new recrystallized ones and the strain hardened ones can lead in turn to another two new families after a new pass. Consequently, after " $n$ " passes, we have to handle $2^{\mathrm{n}}$ families of grains. The situation can become fast impossible to manage, especially for some rolling processes, which involve high number of passes

2) Both families of grains generated at the end of each pass can be merged into just one family, with a weighted average grain size according to the respective fraction of recrystallized and strain hardened grains. This bold assumption can perhaps be applied on carbon or low alloyed steels [4], for which the level of strain necessary for a full completion of recrystallization is rather low (less than $50 \%$ ). This methodology cannot be applied for superalloys: generation of new grains involves significantly higher strain values [5].

3) Between these two extreme approaches, specific treatments of microstructures obtained after each pass can be undertaken, in order to reduce the number of grain families we have to manage, without coming up to just one family as specified above. An example of this methodology can be illustrated by ANAN and col. approach [6], and developed again by TEODORESCU and col. [7].

\section{Specific strategy developed by AUBERT \& DUVAL}

A new strategy is proposed, according to the methodology followed by ANAN or TEODORESCU where some simplifications are considered and based on two main assumptions, which can be easily justified by experience.

First assumption is to consider a fully recrystallized microstructure with an homogenous grain size of $175 \mu \mathrm{m}$, submitted to three identical and isothermal passes, rather close to usual conditions encountered during a hot forming process for 718 alloy: a strain of 0.3 , strain rate equal to $5 \mathrm{~s}^{-1}$, a temperature of $1030{ }^{\circ} \mathrm{C}$ and a holding time between each pass of $5 \mathrm{~s}$. Microstructure calculations according to the first strategy are presented in Figure 1.

The results analysis shows clearly that the new recrystallized grains appeared at each pass are small enough to consider a complete recrystallisation for these specific populations for the next passes, with a size remaining in the same order of magnitude.

In the present case, the thermomechanical conditions applied at each pass are the same, unlike the real process. However, their evolution is generally graduated during bar rolling or ingot conversion. The different populations calculated at a specific location in a product are submitted to the same thermomechanical parameters during one pass, so that the initial grain size is the only one which is different. Consequently, from a practical point of view, it is possible to assume that during a real incremental process, the size of the recrystallized grains remains almost the same. This can be confirmed by examination of samples taken at different steps during a real process, as shown in Figure 2. it can be distinguished two populations of grains: the recrystallized grains which classically appeared equiaxed with a rather homogeneous size and the strain hardened grains with an elongated shape. 


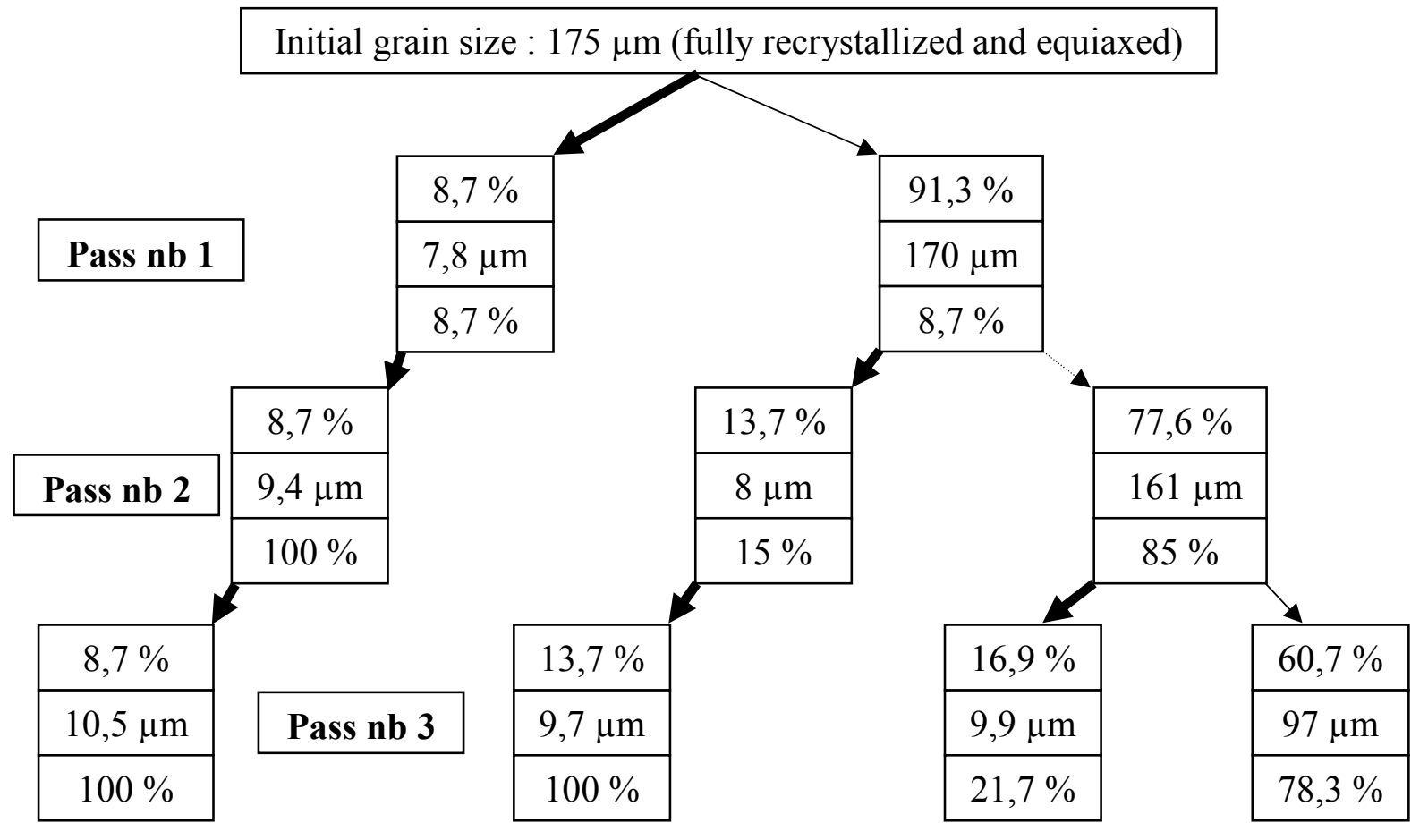

Figure 1- Microstructure evolution during a multi-pass process - in each table, corresponding to one family, data represent successively after each pass: global $\%$, grain size, $\%$ from the mother family - arrows with coarse line are for the recrystallized grains and lean arrows are for the remaining strain hardened grains

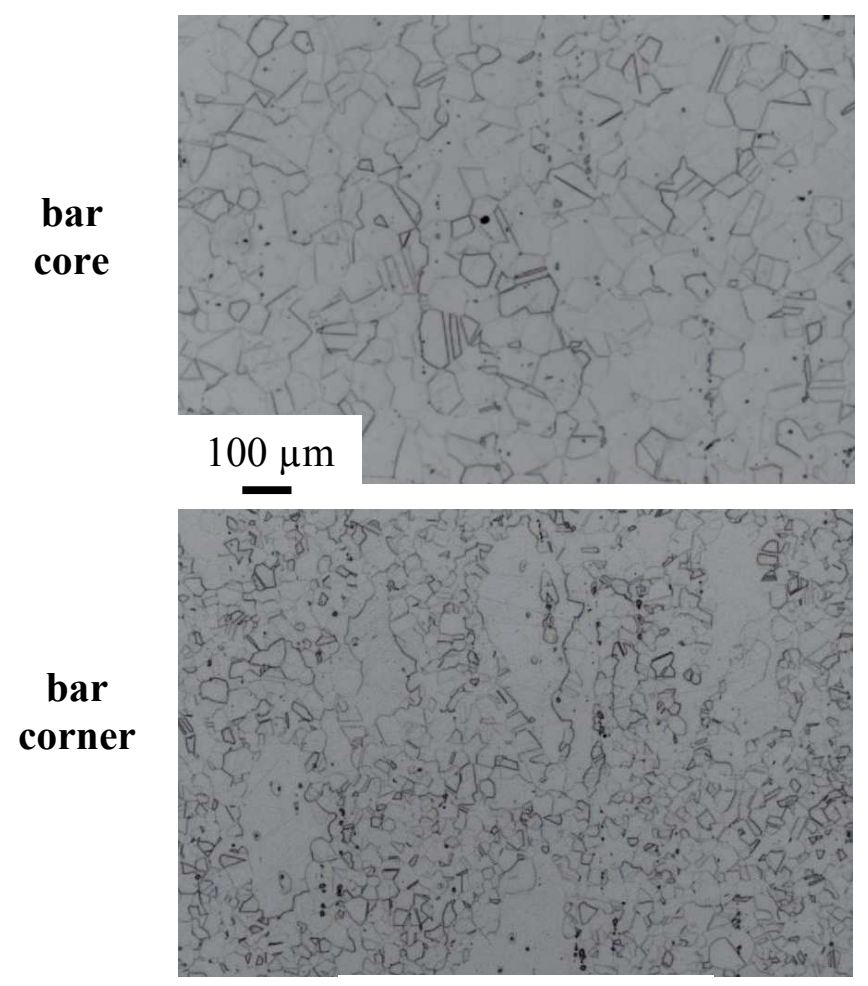

square $78 \mathrm{~mm}$
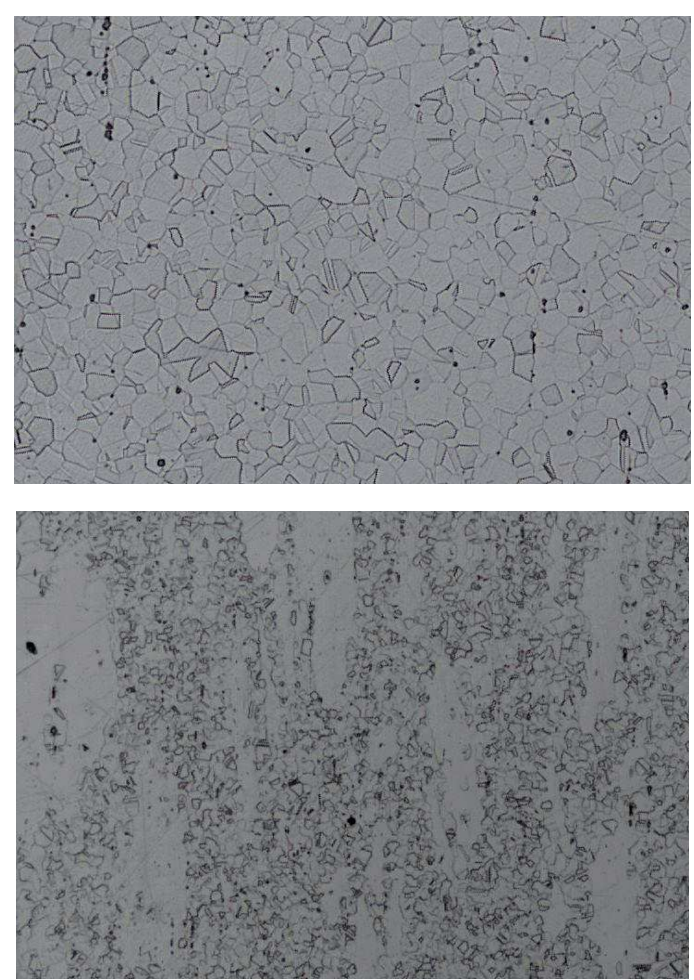

$\varnothing 62 \mathrm{~mm}$

Figure 2 - Microstructure evolution at different steps during rolling of 718 alloy from a $117 \mathrm{~mm}$ square billet to a $62 \mathrm{~mm}$ round bar 
Thus, from a purely numerical point of view, the different populations of recrystallized grains, created at each new pass can be gathered into just one family.

Related to the processing of strain hardened grains and considering the same example as above, Figure 3 shows the comparison between the calculated and measured recrystallized fraction $\mathrm{X}_{\text {tot }}$ as a function of number passes. This is obtained from the relation:

$$
\mathrm{X}_{\mathrm{tot}}=\mathrm{X}_{\mathrm{i}-1}+\left(1-\mathrm{X}_{\mathrm{i}-1}\right) \cdot \mathrm{X}_{\mathrm{i}}
$$

where $\mathrm{X}_{\mathrm{i}}$ and $\mathrm{X}_{\mathrm{i}-1}$ are respectively the recrystallized fraction at the current and at the previous pass, calculated according Avrami formulation, and taking into account at the same time the thermomechanical parameters and the size of the remaining strain hardened grains for each pass.

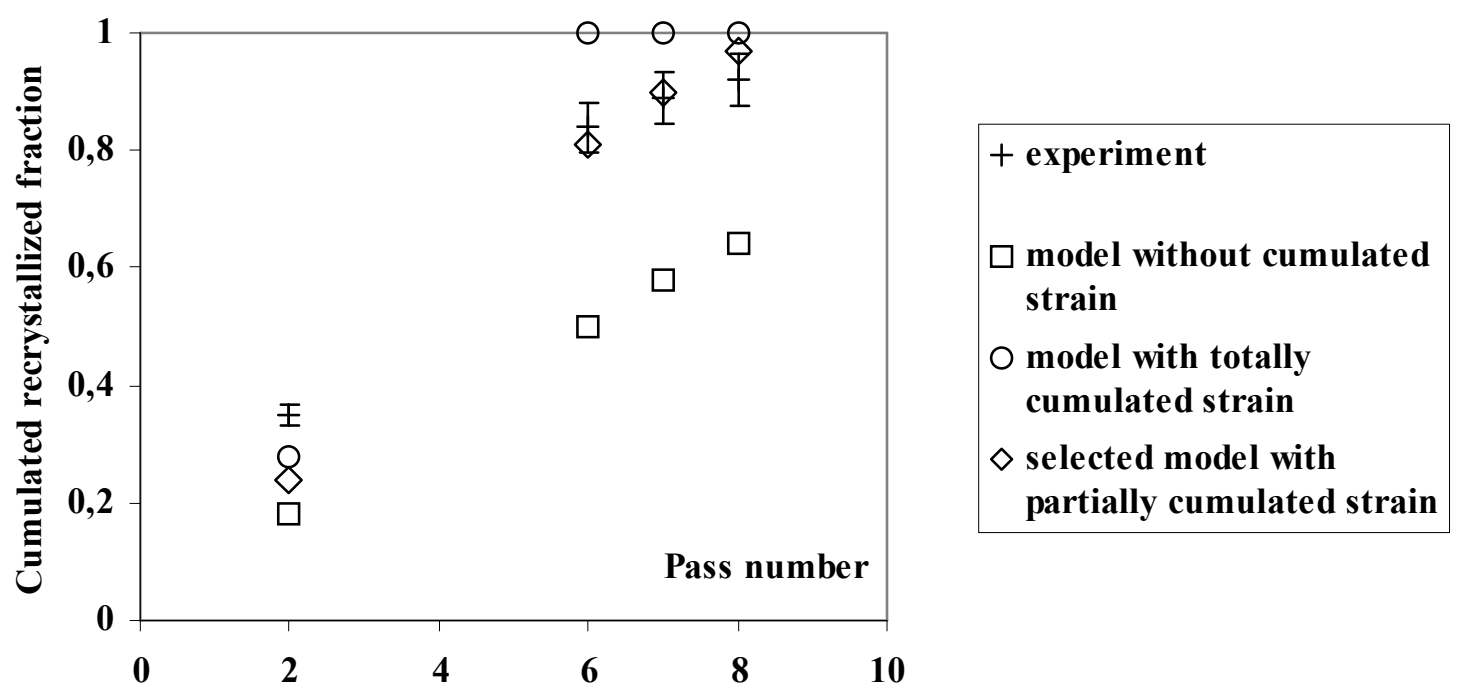

Figure 3 - Comparison between experiment and different models for cumulated recrystallized fraction during multi-pass process at $\mathrm{T}=1030^{\circ} \mathrm{C}$, strain $=0.3-$ strain rate $=0.3 \mathrm{~s}^{-1}$, holding time between each pass $=5 \mathrm{~s}$.

Large discrepancies are observed between our model and the experimental results. The calculated recrystallized fraction is largely underestimated, because for this population of strain hardened grains it is only considered the strain of the current pass, instead of the accumulated strain since the beginning of the test. However, if calculations are carried out with this last way, we overestimate the cumulated recrystallized fraction $\mathrm{X}_{\text {tot. }}$. In fact, only a fraction $\alpha$ of cumulated strain from the previous passes $\varepsilon_{\text {cum }}^{i-1}$ must be taken into account for getting a better agreement, due to softening effects arising during the holding time between two passes.

Finally, for the calculation of $X_{i}$, the equivalent strain at the pass $i, \varepsilon_{i}$, is replaced by $\varepsilon_{\text {cum }}^{i}$, given by the relations:

$$
\left\{\begin{array}{c}
\varepsilon_{\mathrm{cum}}^{\mathrm{i}}=\varepsilon_{\mathrm{i}}+\alpha_{\mathrm{i}-1} \cdot \varepsilon_{\mathrm{cum}}^{\mathrm{i}-1} \\
\varepsilon_{\mathrm{cum}}^{1}=\varepsilon_{1}
\end{array} .\right.
$$

The parameter $\alpha_{\mathrm{i}-1}$ can be in turn defined as a function of the thermomechanical parameters at the pass $\mathrm{i}-1$, by mean of a new set of experiments 


\section{Applications to real rolling sequence}

This methodology has been applied to the case presented in Figure 2. Numerical results shown in Figure 4 are in good agreement with the microstructures observed on the rolled bars. In the core area where temperature is high enough during the process, grains are fully recrystallized, since the first rolling steps. However, their size appears significantly higher than in the remaining part of the bar section, for the same reasons. Finer grains are obtained near the surface, due to the temperature decrease. During all the process, several complete recrystallisation sequences occur (up to 5), except at the surface in four specific areas, where coarse strain hardened grains remain. They correspond to the initial grains obtained after heating of the billet and which are difficult to recrystallize in the former angles of the bar section during the sequences square / diamond / square, where temperature decreases very fast. These grains have just been "eroded" by surrounded recrystallized grains. These areas are marked out in Figure 4 (bottom right map).

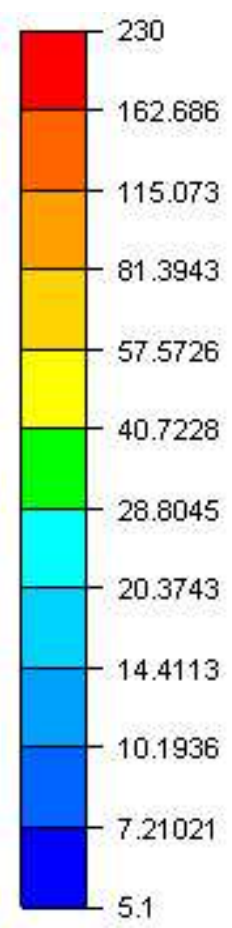

\section{Strain hardened grains}
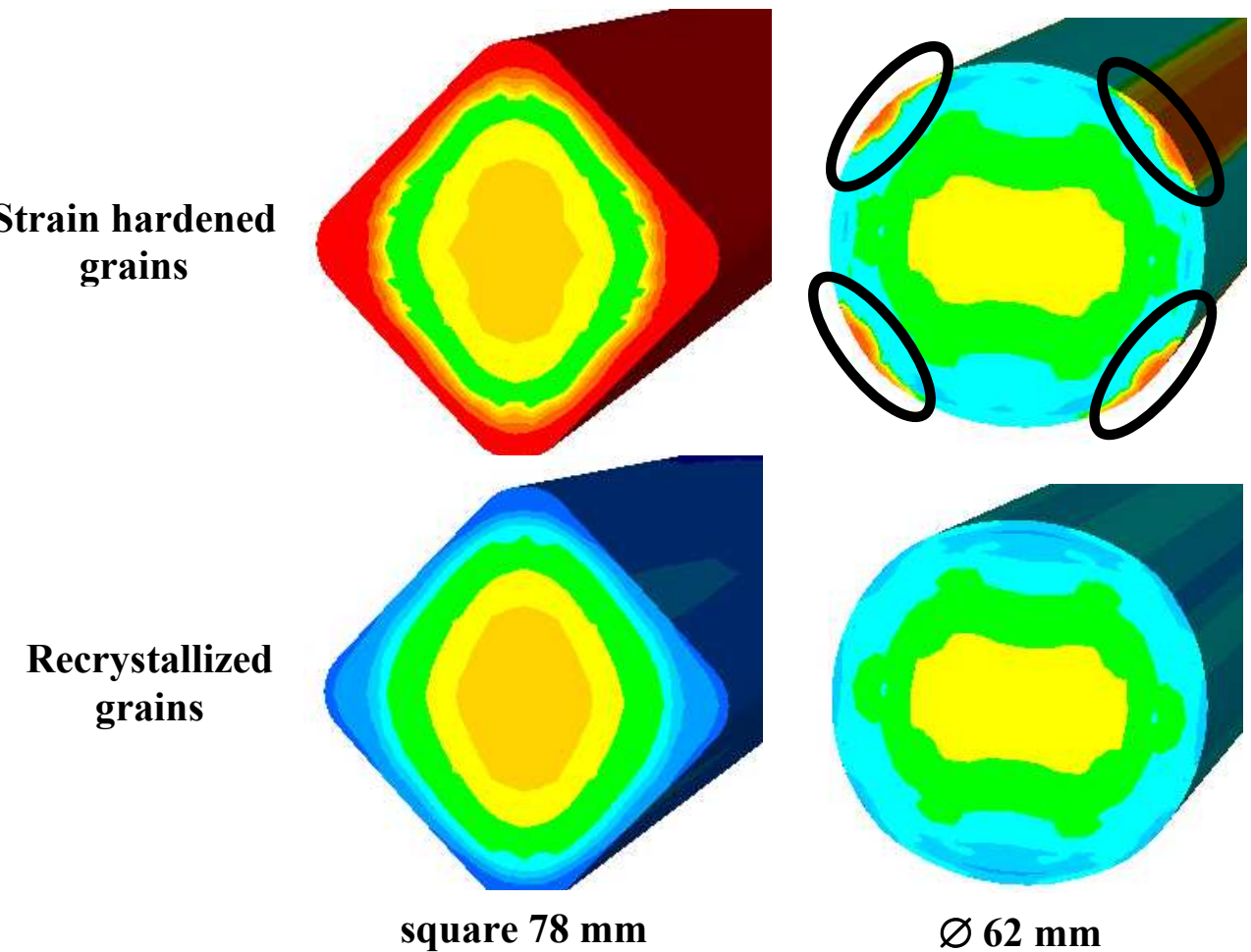

$\varnothing 62 \mathrm{~mm}$

Figure 4 - Grain size prediction in $\mu \mathrm{m}$ at different steps during rolling of 718 alloy from a $117 \mathrm{~mm}$ square billet to a $62 \mathrm{~mm}$ round bar.

The depth of areas with coarse and elongated grains can be significantly reduced with an optimised process by means of modelling. Figure 5 shows clearly the microstructure improvement obtained by geometry changes for the initial billet: a round shape instead of a square with a higher diameter limits the temperature loss when the process starts, leading to a better recrystallization. 

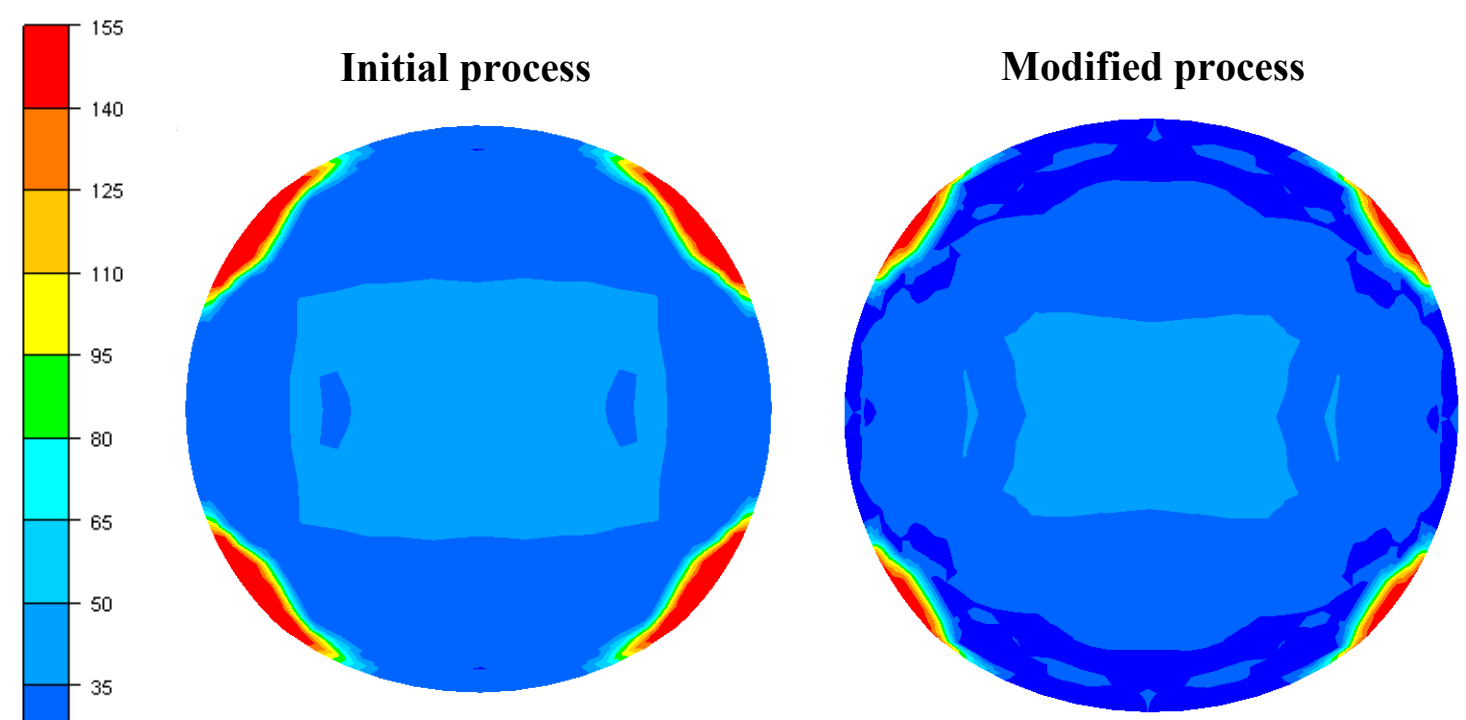

Figure 5 - Size prediction for strain hardened grain in $\mu \mathrm{m}$

\section{Conclusions and prospects}

A specific algorithm for microstructure prediction during incremental process of 718 alloy has been improved and validated for bar rolling, based on experimental considerations. Consequently, the proposed assumption concerning the possibility of gathering grains which have recrystallized at least one time seems to be acceptable. However, some results obtained according to this approach should be analyzed more carefully. For instance, it is possible to calculate the number of recrystallization sequences during the process. Microstructure appears fully recrystallized with a homogenous grain size even if computation leads to a decimal number for the recrystallization fraction. Comparison between this last result and finer microstructure analysis such as level of grain orientation spread by Electron BackScatter Diffraction would be interesting. In the same manner, this last parameter should be compared with the level of softening between each pass $\alpha$, developed in the proposed model.

\section{References}

[1] M. STOCKINGER, J. TOCKNER, Proc. Superalloys 718, 625, 706 and Various Derivates, ed. E.A. Loria, Warrendale, TMS, (2005), 87-95

[2] C.A. DANDRE, S.M. ROBERTS, R.W. EVANS, R.C. REED, Mat. Sci. Tech., Vol. 16 (2000) $14-25$

[3] B. ANTOLOVICH, M. EVANS, Proc. Superalloys 2004, Warrendale, TMS, (2004), 959-968

[4] J.H. BEYNON, C.M. SELLARS, ISIJ International, Vol. 32 (1992), 359-367

[5] J.P. THOMAS, C. DUMONT, F. MONTHEILLET, E. BAUCHET, Proc. Superalloys 2000, Warrendale, TMS, (2000), 39-47

[6] G. ANAN, S. NAKAJIMA, M. MIYAHARA, S. NANBA, M. UMENOTO, A. HIRAMATSU, A. MORIYA, T. WATANABE, ISIJ International, Vol. 32 (1992), 261-266

[7] M. TEODORESCU, P. LASNE, R. LOGE, Mat. Sci. Forum, Vol. 558-559 (2007) 1201-1206 